\title{
Roche and Igen in shotgun wedding
}

On July 24, Roche Holding (Basel, Switzerland) and Igen International (Gaithersburg, MD, USA) ended their sevenyear feud over Roche's license to Igen's electrochemiluminescence (ECL) technology, which is used by Roche's diagnostics division. Publicly announced as "Roche to acquire Igen, securing rights to Igen's Origen technology," the deal was more like Hobson's choice for Roche and hitting the jackpot for Igen.

Roche will pay a total of $\$ 1.26$ billion, a $27 \%$ premium over Igen's closing price of $\$ 37.20$ the day before the announcement, and will spin the company back out. Roche will also give the new Igen, which will be $100 \%$ owned by Igen shareholders, $\$ 150$ million in working capital. In return, Roche receives a nonexclusive license to Igen's technology-to which it once had an exclusive license. In other words, Igen and its shareholders will receive nearly $\$ 1.5$ billion and the return of some rights to its own technology.

Both firms are touting this as a 'win-win' situation. But in reality the deal looks much better for Igen: the biotech saw a $60 \%$ jump in its share price overnight and will keep Roche as its largest licensee (in fiscal year 2003, Roche accounted for $97 \%$ of Igen's royalty income and $63 \%$ of Igen's total revenue). In contrast, $\$ 1.5$ billion may seem expensive to Roche, considering it was paying Igen only about $\$ 40$ million in annual royalties. However, the immunodiagnostic market is estimated to be between $\$ 6-7$ billion and Roche is the current leader in this field; its ECL-based lab diagnostics business had sales of over $\$ 400$ million in 2002, with a nearly $25 \%$ growth rate over the previous three years. Roche apparently anticipates grabbing enough of a market share to make this deal with Igen worthwhile. "Roche obviously did an economic analysis and felt it was worthwhile," says Rick Kaufman, attorney with Heller Ehrman (San Diego, CA, USA).

The story began in 1992, when Igen licensed to Boehringer Mannheim (BMG; Mannheim, Germany) its ECL-based technology (Origen), in which proteins and nucleic acids are coupled to ruthenium chelate and can be detected on the basis of light generated when ruthenium is oxidized/reduced at an electrode surface in the presence of tripropylamine. The license gave BMG the exclusive right to manufacture, market and sell immunodiagnostic products to central hospital laboratories, clinical reference laboratories and blood banks. Igen filed a lawsuit in 1997 against BMG claiming the firm failed to diligently commercialize the licensed technology and to properly compute and pay royalties owed to Igen, among other things. Roche bought BMG's diagnostics business in 1998, and with it came the Igen license and lawsuit.

"The original license was for $9 \%$ royalties, but Roche paid closer to $4-4.5 \%$ without renegotiating the contract," says John Putnam, analyst at Belmont Harbor Capital (Chicago, IL, USA).

In January 2002, a jury awarded Igen $\$ 505$ million in damages, which Roche promptly appealed. Although the US Court of Appeals for the Fourth Circuit (Richmond, VA, USA) lowered that amount to $\$ 18$ million on July 9, 2003 , the court's affirmation of Igen's right to

terminate the license agreement with Roche was the key factor in how the situation played out. "Roche can't be in business without it [a license to Igen's ECL technology]," explains Putnam. "Because of the way they [Roche] acted, they basically screwed themselves. Igen essentially had Roche over a barrel."

Both Kaufman and Putnam agree that this is a unique case, but it underscores the benefits to small biotech companies of sound intellectual property management. Although Igen's original ECL patent was granted in 1991, and will expire in 2011, the firm has regularly patented improvements on the technology (most recently in 1999) to expand the life of its patent portfolio.

Aaron Bouchie, New York

\section{Resistance to $B t$ toxin surprisingly absent from pests}

Defying the expectations of scientists monitoring transgenic crops such as corn and cotton that produce insecticidal proteins derived from Bacillus thuringiensis (Bt), target insect pests have developed little or no resistance to $B t$ crops thus far, according to US Department of Agriculture-funded scientists. These findings suggest that transgenic $B t$ crops could enjoy more extended, more profitable commercial life cycles and that the measures established to mitigate resistance before the crops were introduced are paying off.

"If I'd gotten up seven years ago and said that there would be no evidence of increased $B t$ resistance after $B t$ crops were planted on 62 million hectares [cumulative and worldwide], I would have been hooted off the stage," says entomologist Bruce Tabashnik of the University of Arizona (Tucson, AZ, USA), whose research group recently completed a survey of this phenomenon in collaboration with scientists from Cornell University (Geneva, NY, USA). "No one predicted that there wouldn't even be a minor increase, which is extraordinary."

Nor has Monsanto (St. Louis, MO, USA) seen any signs of resistance to transgenic $B t$ crops, despite widespread use in a number of countries. Graham Head, who is responsible for global coordination of insect resistance management at Monsanto, agrees with Tabashnik's explanation of these findings: "the use of refuges to manage resistance that

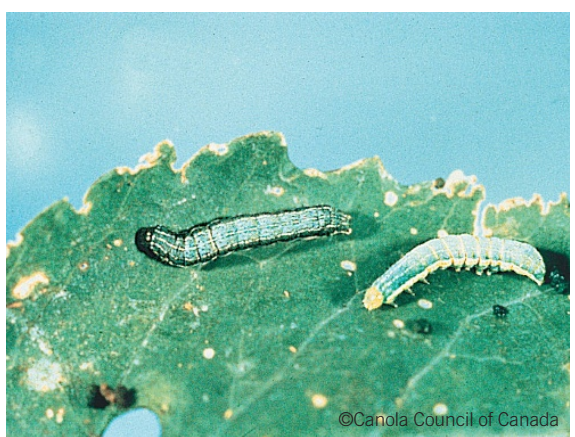

The diamondback moth is the only pest to have evolved resistance to $B t$ sprays used by organic growers, but no pest has evolved resistance to transgenic Bt crops in the field.

tends to be recessive and have fitness costs is a highly effective means of delaying resistance," says Head.

$B t$ transgenic corn entered the commercial arena in 1996 amid extensive, sometimes contentious deliberations over steps needed to avoid or at least retard what some scientists considered the inevitable development by target insects of resistance to these insecticidal proteins, which are encoded in genes carried by soil-dwelling bacteria. Officials at the Environmental Protection Agency (EPA; Washington, DC, USA), working closely with researchers from universities and industry, specified measures for this purpose.

The primary resistance-preventive measure 